\title{
Accuracy of Moving Average Forecasting for NEPSE
}

\author{
Rashesh Vaidya*
}

DOI: https://doi.org/10.3126/jnbs.v13i1.34706

\begin{abstract}
A simple moving average is one of the oldest and the simplest techniques of forecasting the trends of the stock market. The technical analysts follow mainly three types of moving averages, namely; simple, weighted, and exponential moving averages. Among these three types, as per the interest of investors, short-term and long-term time duration is used to calculate the trend using the moving average. All the mentioned moving averages are used by investors or analysts to predict the future trends of the market using historical data. Hence, for evaluating their forecasting accuracy, the paper has used both the short-term and the long-term moving average. The paper has used the NEPSE (closing) index values to calculate as well as plotted the moving averages to forecast the future trend and its accuracy with the help of Mean Absolute Percentage Error (MAPE). The paper found that there is a better crossover in the graphical representation of the moving average in the long-term moving average. In context to the Nepalese stock market, the MAPE results reflected a weekly (5trading days) 5-SMA analysis of the market movement as the most relevant in short-term forecasting. Similarly, using the technique of moving average, 200-SMA (200-trading days of a year) was seen as the most effective to forecast long-term trends. The result of the longterm moving average MAPE pointed out that the annual reports of the listed companies better determine the trend of the market.
\end{abstract}

Keywords: Forecasting accuracy, moving average, moving average crossover

\section{INTRODUCTION}

One of the major premises of efficient market theory is that the market quickly impounds any publicly available information, including macroeconomic information that might be used to predict stock prices. In other words, the term efficiency is used to predict stock prices. In

\footnotetext{
* Mr. Vaidya is a PhD Scholar at Faculty of Management, Tribhuvan University.

Email: vaidyarashesh@gmail.com
} 
general terms, the theory of efficient markets is concerned with whether prices at any point in time fully reflect available information or not (Fama, 1970).

The Efficient Market Hypothesis (EMH) is concerned with the behavior of prices in the assets market. The term "efficient market" was initially applied to the stock market, but the concept was soon generalized to other asset markets (Beechey, Gruen, \& Vickery, 2000). Thus, a market is efficient if all available information is used in pricing securities, i.e., information efficiency.

The University of Chicago, where the EMH was invented, justly became the world's center of academic finance. In 1978, Michael Jensen, a Chicago graduate and one of the creators of the EMH, declared that 'there is no other proposition in economics which has more solid empirical support than the Efficient Markets Hypothesis (Jensen, 1978). Fama $(1970,1976)$ defined three types of efficiency, each of which is based on a different notion of exactly what type of information is understood to be relevant in the phrase "all prices fully reflect all relevant information" (Weston \& Copeland, 2013). It is common to distinguish among three versions of the EMH: the weak, semi-strong, and strong forms of the hypothesis. These versions differ by their notions of what is meant by the term "all available information."

The weak-form hypothesis asserts that stock prices already reflect all information that can be derived by examining market trading data such as the history of past prices, trading volume, or short interest. This version of the hypothesis implies that trend analysis is fruitless. Past stock price data are publicly available and virtually costless to obtain. The weak-form hypothesis holds that if such data ever conveyed reliable signals about future performance, all investors already would have learned to exploit the signals. Ultimately, the signals lose their value as they become widely known because a buy signal, for instance, would result in an immediate price increase (Bodie, Kane, Marcus, \& Mohanty, 2015).

The semi-strong-form hypothesis states that all publicly available information regarding the prospects of a firm must be reflected already in the stock price. Finally, the strong-form version of the efficient market hypothesis states that stock prices reflect all information relevant to the firm, even including information available only to the company insiders (Bodie et al., 2015).

Though, James (1968) had tested the moving average trading strategy far earlier than the development of the Efficient Market Hypothesis. He had found that the signals are generated by a crossing of the price through a moving average of past prices. The moving average is one of the oldest and most popular tools used by technicians. Its strength is as a trendfollowing device which offers the technician the ability to catch major moves. Thus, it is utilized most effectively in trending markets. However, since moving averages are lagging indicators, they can catch a trend only after it has turned (Nison, 1991). The term "moving" in 
moving average is applicable because as the newest data is added to the moving average, the oldest data is dropped. Consequently, the average is always moving as the new data is added. The types of moving averages are based on the time duration. The uses and types of moving averages are based on the short-term or long-term period. The most basic of the moving averages is, as the name implies, the simple moving average. This is the average of all the price points used.

The shorter the term of the moving average, the closer it will "hug" prices. This is a plus in so far as it is more sensitive to recent price action. The negative aspect is that it has a greater potential for whipsaws. Longer-term moving averages provide a greater smoothing effect but are less responsive to recent prices. When a new observation becomes available, the oldest observation in the window is dropped and the new observation is added (i.e., the window slides over the new observation). When calculated over the entire data set $\mathrm{X}$, the SMA provides a smoothed representation of $\mathrm{X}$ where the level of smoothing is proportional to $\mathrm{n}$, the length of the moving average (Larsen, 2010).

A weighted moving average assigns a different weight to each price used to compute the average. Almost all weighted moving averages are front-loaded. That is, the most recent prices are weighted more heavily than the older prices. How the data is weighted is a matter of preference (Nison, 1991).

An exponential moving average developed by Appel (1979) is a special type of weighted moving average. Like the basic weighted moving average, the exponential moving average is front weighted. Unlike other moving averages, though, the exponential moving average incorporates all prior prices used in the data. This type of moving average assigns progressively smaller weights to each of the past prices. Each weight is exponentially smaller than the previous weight, hence, the name exponential moving average (Nison, 1991). Although an investor chooses any one of the moving averages or combined results to determine the future trend, the main concern of an investor is a moving average price crossover.

The moving average of a stock price is the average price over a given interval when that interval is updated as time passes. After a period in which prices have been falling, the moving average will be above the current price (because the moving average continues to average in the older and higher prices until they leave the sample period). In contrast, when prices have been rising, the moving average will be below the current price (Bodie et al., 2015).

A bullish indication is obtained when prices rise up and above the moving average. A bearish signal is obtained when prices are down and get below the moving average. Once in a trend, moving averages will keep an investor in, but also give late signals. While using moving averages do not sell at the top and buy at the bottom. Moving average should not be used in isolation; it should be used with other indicators to benefit in trading (Philippon \& Reshef, 2013). 
The motto of an investor is to generate a higher return with lesser risk from the investment they make in the stock market. An investor might go for buy and hold strategy, some might be swing traders, or might go for buy and sell strategy, as per the market scenario and their portfolio. They are always interested to know about the market trend and catch it. Looking at the trend, an investor would be capable to decide their investment decision. Investors who are aware of technical analysis try to examine past trends and predict future price trajectories. The moving average is the simplest and the oldest technique which is used by an investor to get a signal to buy or sell.

An investor might be using the moving average tool, but they might not be aware which of the moving average will be giving an accurate prediction in the due process of applying for an investment. Thus, this paper attempts to address the forecasting accuracy of short-term and long-term moving average in context to the Nepalese stock market.

\section{LITERATURE REVIEW}

James (1968) tested the buy-sell signal capacity from the monthly moving average calculation for the common stock prices, from 1926 to 1960, maintained by the Center for Research in Securities Prices (CRSP) of NYSE. He concluded that the strategy of the 'buyhold' was seen well at the end of the year with decisions of dividends by the listed companies. Brock, Lakonishok and LeBaron (1992) used the historical data of the Dow Jones Index from 1897 to 1986 and brought out the positive results in the stock market following the moving average trading strategy.

Wong, Manzur and Chew (2003) stated that the technical analysis tools helped an investor to get a signal to enter and exit from the stock market. They found that the most established of the trend followers in the stock market followed the moving average from the study with the members of the Singapore Stock Exchange. Benzion, Klein, Shachmurove and Yagil (2003) tested an efficiency between the S\&P 500 and the Tel-Aviv 25 using the concept of moving average. They found market inefficiency for the Tel-Aviv 25 while testing the two sample markets applying the short-term moving average. They found the better signals of buy, sell, or hold by moving average were sent in the developed market than in the developing stock market.

Sundhar and Kakani (2006) applied the concept of a simple moving average (SMA), and displaced moving average (DMA), to test profiting from the technical analysis tool, namely, moving average in the S\&P CNX, Nifty, and BSE Sensex. They tested the profitability level on five types of SMAs, and DMAs namely, 3-SMA, 5-SMA, 10-SMA, 50-SMA, and 200 SMA, as well as 3-DMA, 5-DMA, 10-DMA, 50-DMA, and 200 DMA respectively. They revealed that the shorter periods of DMA provided better signals to an investor. 
Dzikevicius and Saranda (2010) compared the two rules of technical analysis namely; the exponential moving (smoothing) method, and the simple moving average rule. They applied the two methods on the S\&P 500, and the OMX Baltic Benchmark Index. They then compared the results using the systematic error, i.e., mean square error, mean absolute deviation, mean forecast error, mean absolute percentage error, and the tracking signal evaluation. They concluded from the estimation error analysis that the EMA was more appropriate than the SMA forecast for both the stock markets.

Praekhaow (2010) studied the stocks traded in the set of 50 stocks index of Thailand Stock Market, using three types of moving averages, namely, simple moving average (SMA), weighted moving average (WMA), and an exponential moving average (EMA). He found that the trading strategy by applying SMA brought out 9 percent higher than the remaining two moving averages at the Thailand stock market. Han, Yang and Zhou (2013) applied 10-, 20-, 50-, 100-, and 200-days simple moving average to analyze the stock prices of NYSE and AMEX and found that the moving strategy outperformed a buy-and-hold strategy to other types of technical analysis tools.

Safi and Dawoud (2013) considered three types of moving average namely, simple moving average (SMA), weighted moving average (WMA) and, exponential moving average (EMA), to compare the forecasting accuracy of moving average, in the Palestine stock market. They applied the ARIMA (p,d,q) model, the mean square error, and absolute error, to measure the forecasting accuracy, for the different types of moving average. They found that the 3-days SMA and 3-days EMA were seen accurately for forecasting the PALTEL stock market data than other types of moving average.

Halimawan and Sukarno (2013) found that moving average with the smallest MAD and MAPE is the best method to determine how much the stock price forecasting in a single month. They found an exponential moving average with the least MAD and MAPE, the most suitable for prediction in the Indonesian stock market index, LQ 45. Hansun (2014) introduced a new approach to calculating the moving average by combining the calculation of the weighting factor in WMA and EMA as the new weighting factor. He applied the calculation technique on Jakarta Stock Exchange (1000 JKSE) composite index. He concluded that weighted EMA was seen as the best moving average with the least MAPE to forecast for $100 \mathrm{JKSE}$ composite index.

Lauren and Harlili (2014) pointed out that the daily time-series data of the stock market will help to predict the trend of the market with the help of the SMA. But at the same time, they stated that an investor should also focus on the daily news, particularly financial news, which might have a positive, negative, or neutral impact on the movement of the stock market. Adrian (2015) tested the sensitivity of moving average trading rules performance for the Budapest Stock Exchange. He found that the moving average dual crossover for the shorter period strategy in the stock market could bring out better profitability. 
Anbalagan and Maheswari (2015) applied Fuzzy Metagraph (FM) for decision-making, classification and prediction for the Bombay Stock Exchange (BSE) for a short-term period. They used three technical analysis tools namely, SMA, EMA, RSI and MACD to give input for the FM model. They found that timely accurate news and information to the investors will reduce the level of error (RMSE) in prediction.

De Souza, Ramos, Pena, Sobrei and Kimura (2018) investigated the profitability of the stock markets of the BRICS nations. They found that the buy-hold strategy out-performed the BRICS nations. The strategy of moving average accompanied by other techniques brought out the very strong evidence of outperformance for the stock markets of Russian and India than the remaining BRICS nations.

Raudys and Pabarskaite (2018) stated that the smoothing time series allows removing noise. They stated, in context to finance, moving average helps to smooth the noise in stock prices and helps to forecast trend direction. They proposed Pareto optimized custom moving average, which optimizes weights (one of the parameters is kept in isolation) to obtain most accuracy for a given smoothness or vice-versa. They found that the new proposed custom moving average was more accurate than other moving averages in 99.5 percent of cases on synthetic data and 91 percent of cases on real-world stock data.

Zakamulin and Giner (2020) tested the forecasting accuracy of two trading rules namely, momentum and moving averages. They conducted the correlation coefficient analysis between the actual market return with the SMA, Linear Moving Average (LMA), and EMA, as well as, conducted the test of the relation between the market return, and momentum. They further conducted the robustness test for prediction accuracy, for moving average and momentum. They found that the moving average exhibited more robust forecast accuracy than the momentum for the future direction of price trends.

The study on the use of technical analysis tools, moving average forecasting error, in context to the Nepalese stock market is new. The calculation of the moving average is done with the help of historical data that is used for predicting future trends. Hence, there might be errors in the results of the moving average calculated with the help of the historical data to predict the future trend. The trend shown by the moving average helps an investor to enter or exit from the stock market. The long position or short position to be taken by an investor can be determined from the result of the moving average. The paper regarding the forecasting accuracy for the short-term and long-term moving average will be new in context to the Nepalese stock market.

\section{DATA AND METHODS}

All the recorded daily closing NEPSE Index from the base year (1994) of NEPSE Index are the population of the study. The paper has used the daily closing index (NEPSE Index) of 
Nepal Stock Exchange Limited from the fiscal year 1998-99 to the fiscal year 2019-20 covering 4,876 trading days. The paper assures of no missing data for the considered sample period. The paper has followed the developmental research design to predict future trends. The paper has adopted a trend study to establish patterns of change in the past to predict the future trend or pattern. At the same time, cross-validation has been done with the help of the Mean Absolute Percentage Error (MAPE) to estimate the prediction error of the calculated Moving Average (MA).

Moving averages are running averages of a finite size window over a dataset that can be used as a trend-following device. The moving averages approach empowers one to detrend the time series data without resorting to that sort of machination. The popular moving averages include the four, nine, and 18-days averages for shorter-term traders and the 13-, 26, and 40-week moving averages for position players (Nison, 1991). The moving average analysis is done on the time-basis, namely, the shorter term and longer term. The paper has considered 5 and 20 days as the shorter-term and 50,100 and 200 days respectively as the longer-term. Similarly, a graphical representation of the moving averages is compared with the actual NEPSE daily closing index of the stock market. The paper has used Microsoft Excel to calculate the required moving average, prediction accuracy-related values, and to generate the graphs. The paper has used the moving average formulas used by Lukac, Brorsen and Irwin (1988) and Brock, Lakonishok and LeBaron (1992).

$$
\begin{aligned}
& \therefore \text { Simple Moving Average }\left[\operatorname{SMA}_{t}(n)\right]=\frac{1}{n} \sum_{i=1}^{n} P_{t-i} \\
& \therefore \text { Weighted Moving Average }\left[W M A_{t}(n)\right] \\
& \quad=\frac{\sum_{i=1}^{n} W_{t-i} P_{t-i}}{\sum_{i=1}^{n} P W_{t-i}} \text {, where } W \text { is weighting factor }
\end{aligned}
$$

$\therefore$ Exponential Moving Average $\left[\operatorname{EMA}_{t}(n)\right]=(1-\lambda) \sum_{i=0}^{\infty} \lambda^{i} P_{t-i}$, where $\lambda=\frac{n-1}{n+1}$

The paper has used the scale-dependent measure for measuring the forecasting accuracy. The paper has adopted the formula to measure forecasting accuracy in time-series data that are theoretically relevant in statistical modelling as defined by Hyndman (2013). They are namely, Mean Sum of Error (MSE) and Root Mean Square Error (RMSE). Similarly, the absolute measure of error, Mean Absolute Percentage Error (MAPE) derived by Makridakis et al. (1982) has also been used in the paper.

$$
\begin{gathered}
\therefore \text { Mean Sum of Error }(M S E)=\sum_{i=1}^{n} \frac{\left[A_{i}-F_{i}\right]^{2}}{n} \\
\therefore \text { Root Mean Sum of Error }(R M S E)=\sqrt{\sum_{i=1}^{n} \frac{\left[A_{i}-F_{i}\right]^{2}}{n}}
\end{gathered}
$$

where, $\mathrm{A}_{\mathrm{i}}=$ Actual Data and $\mathrm{F}_{\mathrm{i}}=$ Forecasted Data 
$\therefore$ Mean Absolute Percentage Error (MAPE) $=\frac{1}{n} \sum_{i=1}^{n}\left|\frac{A_{i}-F_{i}}{A_{i}}\right| x 100$

where, $\mathrm{A}_{\mathrm{i}}=$ Actual Data and $\mathrm{F}_{\mathrm{i}}=$ Forecasted Data

The value of MAPE measures the prediction accuracy of the forecasting method for moving average calculation. It usually expresses the accuracy as a ratio. The smaller value of MAPE reflects better prediction accuracy and vice versa.

\section{RESULTS AND DISCUSSION}

\subsection{Short-term Moving Average Analysis}

A short-term moving average is faster as it considers the index for a shorter period and more reactive to the daily changes. The short-term moving average tends to smooth out the noise better than the long-term moving average. The paper has considered five days and twenty days as the shorter period moving average (MA). The following line graph shows the comparative-representation between the actual daily closing index of the NEPSE Index and the respective time-based moving averages for the shorter-term.

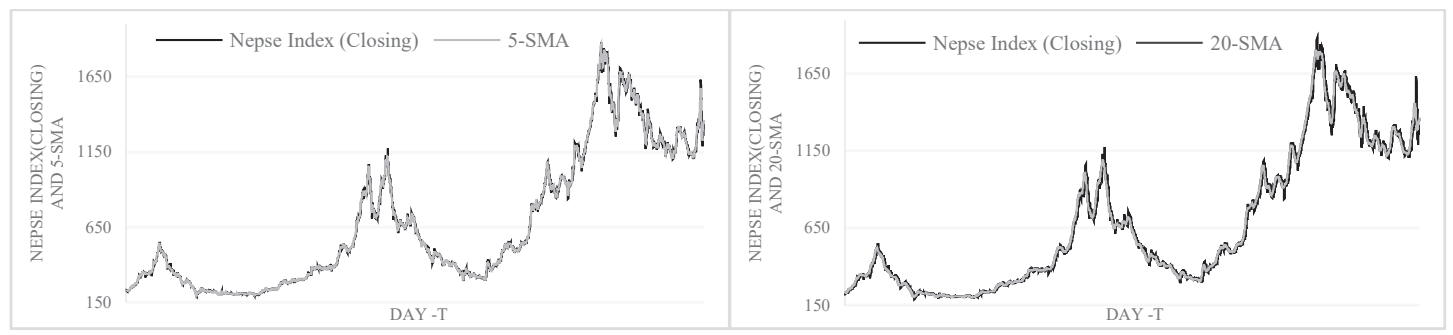

Figure 1. 5-SMA and 20-SMA with NEPSE Index (closing).
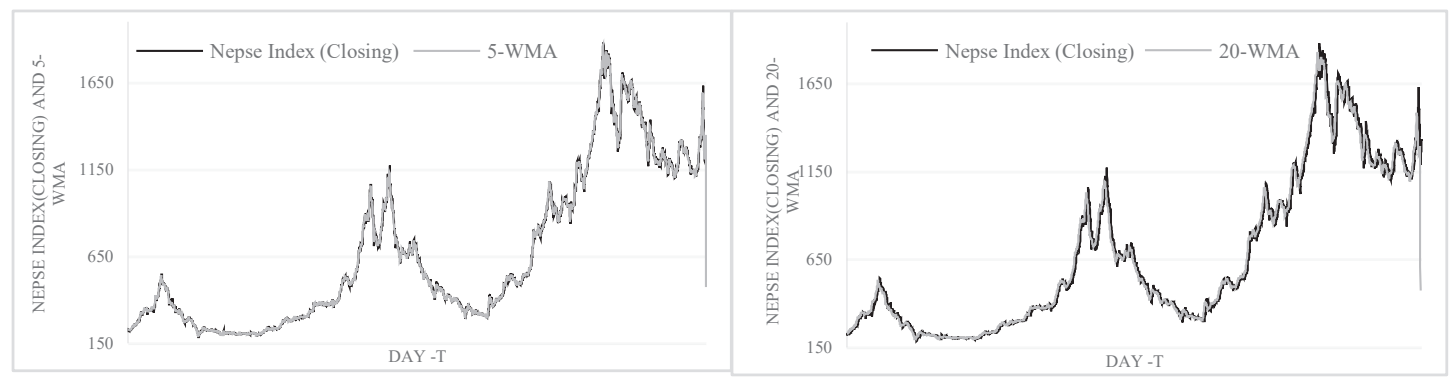

Figure 2. 5-WMA and 20-WMA with NEPSE Index (closing). 


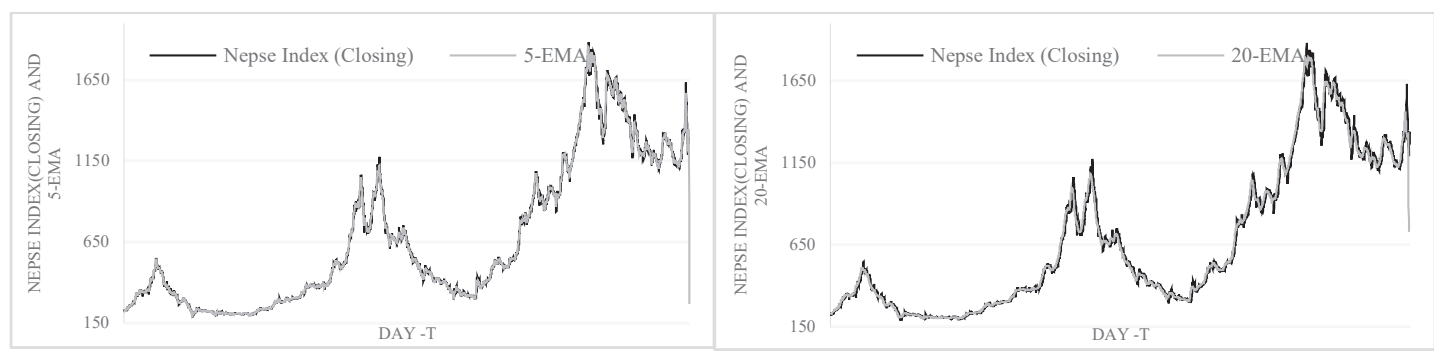

Figure 3. 5-EMA and 20-EMA with NEPSE Index (closing).

The line graph for all the short-term MA is seen moving tightly with the actual daily closing NEPSE Index reflecting no clear observation of the crossover scenario. Thus, it is difficult to observe a crossover point for a shorter MA immediately on the graphical representation.

\subsection{Long-term Moving Average Analysis}

A long-term moving average is lesser sensitive to immediate noise. An investor who is not interested in a sudden sharp change and waits for the bigger picture of the performance prefers the long-term moving average (MA). The long-term MA has some lagging in indicating the effects in the market movement. Fifty days, a hundred days and two-hundred days are considered as the longer period moving average (MA) for the paper. The following line graph shows the comparative representation between the actual daily closing index of the NEPSE Index and the respective time-based moving averages for the longer-term.

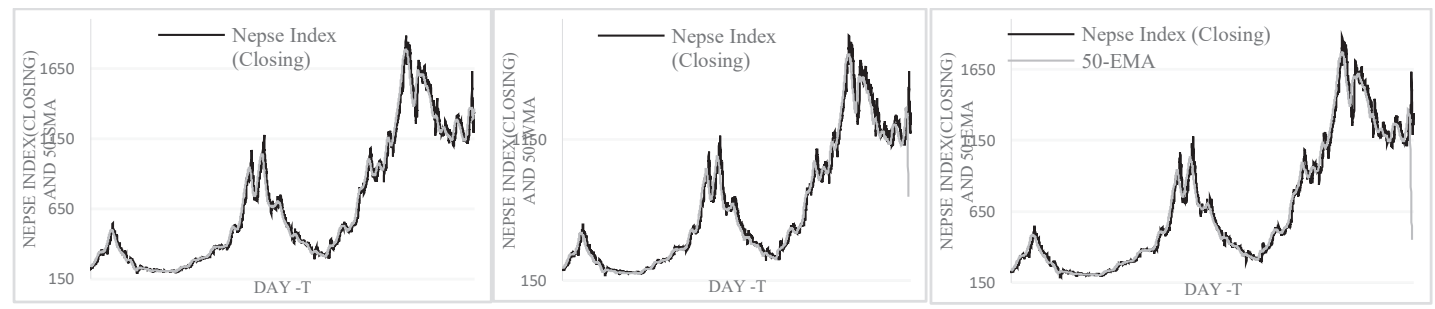

Figure 4. 50-SMA, 50-WMA and 50-EMA with NEPSE Index (closing).

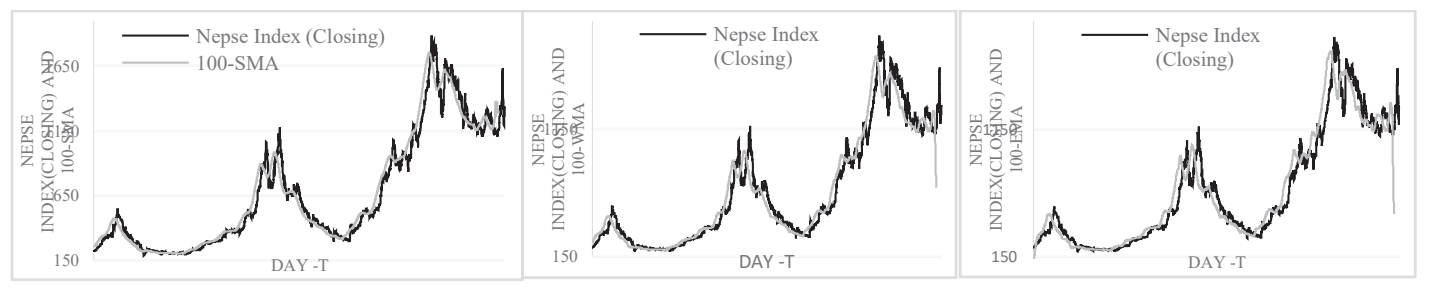

Figure 5. 100-SMA, 100-WMA and 100-EMA with NEPSE Index (closing). 


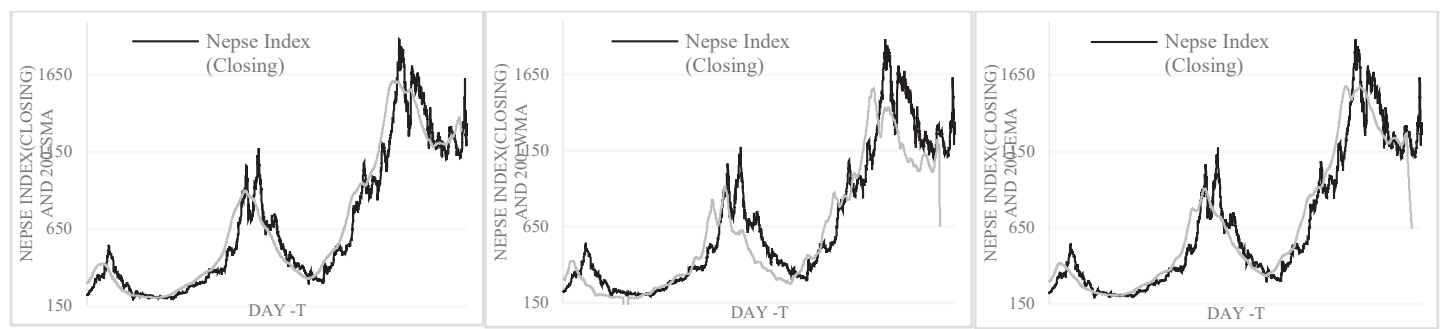

Figure 6. 200-SMA, 200-WMA and 200-EMA with NEPSE Index (closing).

The line graph for the longer MA is seen properly visualizing the clear crossover. The crossover can be visualized for the 100-days and 200-days MA. When the daily NEPSE Index (closing) is seen moving above the MA, the market is showing a bullish trend and viceversa. A proper indication is visualized in the longer periods SMA due to the availability of the authentic financial (fundamental) information in the market.

\subsection{Forecasting Accuracy of Moving Average Analysis}

The paper has followed MAPE to measure the forecasting accuracy of MA for different periods. The MAPE results for the forecasting accuracy of the short-term MA and long-term MA are discussed below:

\subsubsection{Forecasting Accuracy of Short-term Moving Average}

Table 1 shows the results of the forecasting accuracy of the short-term moving average:

Table 1

Forecasting Accuracy of Short-term Moving Average

\begin{tabular}{llll}
\hline Moving averages & MSE & RMSE & MAPE \\
\hline 5-SMA & 0.0686 & 0.2618 & 0.0003 \\
20-SMA & 1.0963 & 1.0470 & 0.0014 \\
5-EMA & 0.0702 & 0.2650 & 0.0007 \\
20-EMA & 0.2848 & 0.5337 & 0.0215 \\
5-WMA & 0.0323 & 0.1796 & 0.0004 \\
20-WMA & 0.9088 & 0.9533 & 0.0668 \\
\hline
\end{tabular}

Source: Annex-I

The value of MAPE reflects the prediction accuracy of the forecasting of the moving average. Simply, the value of MAPE measures the magnitude of the prediction error. Hence, the lesser the value of MAPE, the better the forecasted value closer to the actual value. A 5- 
days SMA (5-SMA) is seen as the most suitable in context to the forecasting accuracy under the short-term period with the least MAPE (0.0003), followed by the 5-WMA (MAPE: 0.0004). A 20-days WMA (20-WMA) is not seen as suitable for forecasting the NEPSE movement for a short time duration, with the highest MAPE (0.0668).

The above results reflect that among the short-term moving average for different periods, 5-days MA for three types of MA gave a better prediction accuracy with very minimal error, in context to NEPSE in comparison to 20-days MA. Among the three types of MA, comparatively, 5-SMA was with the least percent of MAPE, reflecting the MA very much closer to the actual NEPSE movement.

The shorter the time span used in calculating the MA, the more sensitive to the changes in the prices. NEPSE index is based on the market capitalization, hence, the small changes in the price of the listed shares reflect in the index-based short-term MA. Hence, this makes a short-term MA closer to the actual movement of the NEPSE.

\subsubsection{Forecasting Accuracy of Long-term Moving Average}

Table 2 shows the results of the forecasting accuracy of the long-term moving average:

Table 2

Forecasting Accuracy of Long-term Moving Average

\begin{tabular}{llll}
\hline Moving Averages & MSE & RMSE & MAPE \\
\hline 50-SMA & 0.4096 & 0.6400 & 0.0021 \\
100-SMA & 7763.08 & 88.1083 & 8.0554 \\
200-SMA & 3.7872 & 1.9461 & 0.0019 \\
50-EMA & 0.3312 & 0.5750 & 0.0021 \\
100-EMA & 17.3087 & 4.1604 & 5.7011 \\
200-EMA & 2.6506 & 1.6281 & 0.0056 \\
50-WMA & 0.4096 & 0.6400 & 0.0021 \\
100-WMA & 1.7691 & 1.3301 & 0.2190 \\
200-WMA & 7.0082 & 2.6473 & 0.6279 \\
\hline
\end{tabular}

Source: Annex-I

A 200-days SMA (200-SMA) is seen as the most suitable in context to the forecasting accuracy under the long-term period with the least MAPE (0.0019), followed by the 50-SMA as well as 50-EMA with equal MAPE (MAPE: 0.0021). As well as 200-SMA (MAPE: $0.0056)$ is seen better for a longer duration. A 100-days SMA (100-SMA) is not seen as suitable for forecasting the NEPSE movement for the longer period having the highest MAPE (8.0554). Similarly, a 100-days EMA is not seen providing accurate prediction for the NEPSE, as the value of MAPE (5.7011) is seen relatively high after the MAPE for 100-SMA. 
This reflects that the quarterly published reports of the listed companies are not influencing the market movement.

The value of MAPE for the longer period MA is not seen as suitable in context to NEPSE, as the value of MAPE for all the longer period MA are seen comparatively higher than that of the shorter period MA. Especially, 100-SMA and 100-EMA seem not reliable for forecasting the NEPSE movement under the long-term period.

\section{CONCLUSION AND IMPLICATIONS}

A moving average is one of the oldest and simplest techniques of technical analysis. There are three types of MA, namely, simple, exponential, and weighted practiced by investors. Nevertheless, there are other types of MA, namely, double, triple, smoothed, zerolag, and much more applied and practiced by investors. The choice of the MA is seen based on accuracy, smoothness, and filtering the best signal from the market.

The paper attempts to identify the best time-period MA for the short-period, as well as for the long-period for the Nepalese stock market, NEPSE, with the least forecasting error. A graphical representation for the short-term MA was not able to reflect the crossover scenario, as well as forecasting accuracy, in comparison to long-term MA. The numerical calculation for the forecasting accuracy, namely, MAPE, brought out a clear picture. The 5-SMA, shortterm MA, produced the best forecasting accuracy with the least MAPE (0.0003). This result shows the market movement during trading days in a week will be more fruitful to predict the coming week pattern of return at NEPSE, as the trading floor of NEPSE opens for five days a week. Though, the minimal difference is seen in MAPE value for three different types of MA, namely; SMA, WMA, and EMA. At the same time, 20-WMA is not seen as suitable, in context to MAPE (0.0668), with the highest value in the short term period.

In context to long-term MA, the value of MAPE for 50 days three different types of MA are seen at the same value (0.0021). At the same time, 100-days MA is seen not suitable, in context to make a prediction in NEPSE, with a high MAPE value. This shows that prediction for the market movement, looking at the quarterly reports of the listed companies, especially banks and financial institutions, as well as insurance companies will not be productive in NEPSE. Similarly, in context to the long-term, the 200-days SMA is seen as the best forecaster with the least MAPE (0.0019). The result from the MAPE reflects the shorter period MA with lesser error in the forecasted value. Therefore, if considered for predicting the future trend of the NEPSE, short-term MA is seen as appropriate. Hence, in context to NEPSE, the shorter period MA is seen as more suitable for foresting the trend of the market rather than the longer period MA. The result from the MAPE reflects the shorter period with lesser error in the forecasted value if consider for predicting the future trend of the market. Therefore, the prediction accuracy was seen well in shorter MA than longer MA. 
Similarly, the SMA provides the most smoothing result that helps to find out the support and resistance to an investor. At the same time, if the investor is concerned with the lag effect in return, then WMA and EMA will be the better options that capture the recent price and give less emphasis to older prices. An investor could also apply the concept of the closing price of an individual company's daily closing market price of the share for better interpretation. Hence, they can picture out the buy and sell signals looking at the crossover points.

\section{REFERENCES}

Adrian, Z-I. (2015). The sensitivity of moving average trading rules performance with respect to methodological assumptions. Procedia Economics and Finance.32, 1353-1361. Retrieved from https://doi.org/10.1016/S2212-5671(15)01512-9

Anbalagan, T., \& Maheswari, S.U. (2015). Classification and prediction of stock market index based on fuzzy metagraph. Procedia Computer Science. 47, 214-221. Retrieved from https://doi.org/10.1016/j.procs.2015.03.200

Appel, G. (1979). The moving average convergence divergence trading method. New York: Signalert Corp.

Beechey, M., Gruen, D., \& Vickery, J. (2000, January). The efficient market hypothesis: A survey. RBA Research Discussion Papers, pp. 1-30. Retrieved from https://doi.org/ RePEc:rba:rbardp:rdp2000-01

Benzion, U., Klein, P., Shachmurove, Y., \& Yagil, J. (2003). Efficiency differences between the S\&P 500 and the Tel-Aviv 25 Indices: A moving average comparison. International Journal of Business, 8(3), 267-284. Retrieved from https://doi.org/10.2139/ssrn.420243

Bodie, Z., Kane, A., Marcus, A.J., \& Mohanty, P. (2015). Investments. New Delhi: McGraw Hill Education (India) Private Limited.

Brock, W., Lakonishok, J., \& LeBaron, B. (1992). Simple technical trading rules and the stochastic properties of stock returns. Journal of Finance, 47(5), 1731-1764. Retrieved from https://doi.org/10.2307/2328994

De Souza, M.J.S., Ramos, D.G.F., Pena, M.G., Sobrei, V.A., \& Kimura, H. (2018). Examination of the profitability or technical analysis based on moving average strategies in BRICS. Financial Innovation, 4(3), 1-18. Retrieved from https://doi.org/10.1186/s40854-018-0087-z

Dzikevicius, A., \& Saranda, S. (2010). EMA versus SMA usage to forecast stock markets: The case of S\&P 500 and OMX Baltic benchmark. Verslas: teorija ir praktika, 11(3), 248-255. Retrieved from https://doi.org/10.3846/btp.2010.27

Fama, E.F. (1970). Efficient capital market: A review of theory and empirical work. The Journal of Finance, 25(2), 383-417. Retrieved from https://doi.org/10.2307/2325486 
Fama, E.F. (1976). Efficient capital markets: Reply. The Journal of Finance, 31(1), 143-145. Retrieved from https://doi.org/10.2307/2326404

Han, Y., Yang, K., \& Zhou, G. (2013). A new anomaly: The cross sectional profitability of technical analysis. Journal of Financial and Quantitative Analysis, 48(1), 1433-1461. Retrieved from https://doi.org/10.1017/S0022109013000586

Hansun, S. (2014). A novel research of new moving average method in time series analysis. International Journal of New Media Technology (IJNMT), 1(1), 22-26.

Halimawan, A. A., \& Sukarno, S. (2013). Stock price forecasting accuracy analysis using Mean Absolut Deviation (MAD) and Mean Absolute Percentage Error (MAPE) on smoothing moving average and exponential moving average indicator (Empirical study 10 LQ 45 stock with largest capitalization from period Feb-Jul 2013). The Indonesian Journal of Business Administration, 2 (13), 1613-1626.

Hyndman, R.J. (2013). Forecasting: Principles and Practice. Perth: University of Western Australia.

James, F.E. (1968). Monthly moving average-An effective investment tools? Journal of Financial and Quantitative Analysis, 3(3), 315-326. Retrieved from https://doi.org/10.2307/2329816

Jensen, M. (1978). Some anomalous evidence regarding market efficiency. Journal of Financial Economics, 6(2-3), 95-101. Retrieved from https://doi.org/10.1016/0304405X(78)90025-9

Larsen, J.I. (2010). Predicting Stock Prices Using Technical Analysis and Machine Learning. Department of Computer and Information Science. Oslo:Norwegian University of Science and Technology.

Lauren, S., \& Harlili, S.D. (2014). Stock trend prediction using simple moving average supported by news classification. 2014 International Conference of Advanced Informatics: Concept, Theory and Application (ICAICTA). (pp. 135-139). Bandung. Retrieved from https://doi.org/10.1109/ICAICTA.2014.7005929

Lukac, L.P., Brorsen, B.W., \& Irwin, S.H. (1988). A test of futures market disequilibrium using twelve different technical trading systems. Applied Economics, 20(5), 623-639. Retrieved from https://doi.org/10.1080/00036848800000113

Makridakis, S., Anderson, A., Carbonr, R., Fildes, R., Hibon, M., Lewandowski, R., Newton, J., Parzen, E., \& Winkler, R. (1982). The accuracy of extrapolation (time series) methods: Results of a forecasting competition. Journal of Forecasting, 1(2), 111-153. Retrieved from https://doi.org/10.1002/for.3980010202

Nison, S. (1991). Japanese candlestick charting techniques. New York: New York Institute of Finance. 
Philippon, T., \& Reshef, A. (2013). An international look ar the growth of modern finance. Journal of Economic of Economic Perspective, 27(2), 73-96. Retrieved from https://doi.org/10.1257/jep.27.2.73

Praekhaow, P. (2010). Determination of trading points using the moving average methods. GMSTEC 2010: International Conference for a Sustainable Greater Mekong Subregion (pp. 1-5). Bangkok: KMUTT.

Raudys, A., \& Pabarskaitw, Z. (2018). Optimizing the smoothness and accuracy of moving average for stock price data. Technological and Economic Development of Economy, 24 (3), 984-1003. Retrieved from https://doi.org/ 10.3846/20294913.2016.1216906

Safi, S.K., \& Dawoud, I.A. (2013). Comparative study on forecasting accuracy among moving average models with simulation and PALTEL stock market data in Palestine. American Journal of Theoretical and Applied Statistics, 2(6), 202-209. Retrieved from https://doi.org/10.11648/J.AJTAS.20130206.17

Sundhar, S., \& Kakani, R.R. (2006, March). Profiting from technical analysis in Indian equity markets: Using moving averages. XLRI Working Paper, 06-02, pp. 1-20. Retrieved from http://dx.doi.org/10.2139/ssrn.889515

Weston, J., \& Copeland, T. (2013). Financial theory and corporate policy. New Delhi: Pearson Education.

Wong, W-K., Manzur, M., \& Chew, B-K. (2003). How rewarding is technical analysis? Evidence from Singapore stock market. Applied Financial Economics, 13(7), 543551. Retrieved from https://doi.org/10.1080/0960310022000020906

Zakamulin, V., \& Giner, J. (2020). Trend following with momentum versus moving averages: A tale of differences. Quantitative Finance, 20(6), 985-1007. Retrieved from https://doi.org/10.1080/14697688. 2020.1716057

Annex-I: Moving Averages

\begin{tabular}{lrrrr}
\hline Moving Averages & {$\left[A_{i}-F_{i}\right]^{2}$} & MSE & RMSE & MAPE \\
\hline 5-SMA & 334.31 & 0.0686 & 0.2618 & 0.0003 \\
20-SMA & 5345.52 & 1.0963 & 1.0470 & 0.0014 \\
50-SMA & 1997.07 & 0.4096 & 0.6400 & 0.0021 \\
100-SMA & 37852762.92 & 7763.08 & 88.1083 & 8.0554 \\
200-SMA & 18466.34 & 3.7872 & 1.9461 & 0.0019 \\
5-EMA & 342.36 & 0.0702 & 0.2650 & 0.0007 \\
20-EMA & 1388.75 & 0.2848 & 0.5337 & 0.0215 \\
50-EMA & 1614.93 & 0.3312 & 0.5750 & 0.0021 \\
100-EMA & 84397.02 & 17.3087 & 4.1604 & 5.7011 \\
200-EMA & 12924.47 & 2.6506 & 1.6281 & 0.0056 \\
5-WMA & 157.29 & 0.0323 & 0.1796 & 0.0004 \\
20-WMA & 4431.19 & 0.9088 & 0.9533 & 0.0668 \\
50-WMA & 1997.07 & 0.4096 & 0.6400 & 0.0021 \\
100-WMA & 8626.20 & 1.7691 & 1.3301 & 0.2190 \\
200-WMA & 34172.12 & 7.0082 & 2.6473 & 0.6279 \\
\hline
\end{tabular}

